\title{
Elemen Nature Sustainable Infrastructure di Wetland Park Bandung Timur
}

\author{
Dwi Kustianingrum ${ }^{1}$, Resha Lutfiarna ${ }^{1}$, Muhammad Alfiansyah ${ }^{1}$, Monica Cindy ${ }^{1}$ \\ ${ }^{1}$ Prgram Studi Arsitektur, Fakultas Arsitektur dan Desain \\ Itenas, Institut Teknologi Nasional Bandung \\ Email: dwie@itenas.ac.id
}

\begin{abstract}
ABSTRAK
Pembangunan infrastruktur yang kian marak mengakibatkan berkurangnya secara pesat lahan hijau dan pertanian di setiap daerah Kota Bandung yang beralih fungsi menjadi kawasan pemukiman dan bisnis baru. Dampak dari berkurangnya lahan hijau dan pertanian di Kota Bandung adalah berkurangnya daya serap air di saat curah air hujan tinggi dan mengakibatkan banjir yang berkelanjutan, salah satunya yaitu daerah Gedebage. Pemerintah Kota Bandung memberikan solusi terhadap banjir yaitu dibuatnya Kawasan Wetland Park yang berlokasi di Desa Cisurupan, Cibiru, Kota Bandung. Penelitian ini dilakukan dengan tujuan untuk mengidentifikasi elemen landscape (lanskap), wetland (lahan basah), water management (manajemen air), dan pengendalian alam Kawasan Wetland Park Cisurupan sebagai bagian dari Nature Infrastructure dalam konsep Sustainable Infrastructure. Metode penelitian yang digunakan adalah deskriptif analisis kualitatif. Adapun simpulan dari bahasan ini yaitu kawasan dibuat sebagai daerah resapan air hujan, salah satunya melalui wetland buatan berupa kolam retensi. Pentingnya dibuat wetland dengan penataan landscape sebagai pengendali banjir dan sirkulasi air dari buangan air hujan yang diatur melalui sungai untuk direkayasa dengan cara dibelokkan ke dalam kolam retensi. Kawasan ini menjadi strategi untuk menciptakan lingkungan yang sehat melalui tanaman yang ada pada kawasan ini agar bermanfaat bagi kawasan Wetland Park Cisurupan dan lingkungan sekitarnya sebagai pengendalian alam
\end{abstract}

Kata kunci: Air hujan, Banjir, Kolam Retensi, Nature Infrastructure, Suistanable Infrastructure, Wetland Park

\begin{abstract}
The rapid development of infrastructure is currently affecting the reduction of green land and agriculture in each area in Bandung, which switch its function into a residential area and a new business district. The impact of the reduction of green land and agriculture in Bandung, is less of water absorption in the city and also whenever it is raining, the absorbent of soil decreased which resulted in a continuous flood. One of the case is in Gedebage area. Bandung City government provides solutions to the flood that is created by the area Wetland Park located in Cisurupan Village, Cibiru, City of Bandung. This research is done with the aim to identify landscape elements, wetland (wetlands), water management, and natural control of the area Wetland Park Cisurupan as part of Nature Infrastructure in the concept Sustainable Infrastructure. The research method used is a descriptive qualitative analysis. The conclusion of this discussion is the area made as a catchment area of rain, one of them through artificial wetland in the form of a retention pool. The importance of the wetland is made with the arrangement of landscape as flood control and water circulation of rainwater waste that is arranged through the river to be engineered by being bent into the retention pondl. This area is a strategy to create a healthy environment through plants that exist in this area in order to benefit for the area Wetland Park Cisurupan and the surrounding environment as natural control.
\end{abstract}

Keywords: Rainwater, Flood, Retention Pond, Nature Infrastructure, Suistanable Infrastructure, Wetland Park 


\section{PENDAHULUAN}

Manusia sebagai mahluk hidup dalam menjalani kehidupannya selalu tak lepas dari ekosistemnya. Seperti diketahui, ekosistem adalah suatu sistem ekologi yang terbentuk oleh hubungan timbal balik tak terpisahkan antara makhluk hidup dengan lingkungannya. Ekosistem dapat dikatakan juga suatu tatanan kesatuan secara utuh dan menyeluruh antara segenap unsur lingkungan hidup yang saling memengaruhi.[1]

Dalam tatanan ekosistem, terdapat studi -studi yang menunjukkan bahwa ada keterkaitan antara layanan yang spesifik dari ekosistem, berupa relasi antara karakter biofisik dari lansekap, fungsi, layanan, keuntungan dan nilai -nilai bagi masyarakat.[2] Layanan ekosistem terkait kebutuhan air dengan dampak yang berkaitan dengan aspek lain dapat diupayakan melalui integrasi constructed wetlands dengan perancangan tata lansekapnya.

Wetland atau lahan basah merupakan wilayah-wilayah di mana keberadaan tanahnya jenuh dengan air, bersifat permanen atau musiman. Wetland dapat berupa air diam ataupun mengalir, terbentuk secara alami ataupun buatan manusia, dan umumnya bercirikan tinggi muka air yang dangkal, dekat dengan permukaan tanah, dan memiliki jenis tumbuhan yang khas.[3]

Wetland merupakan area-area transisi antara tanah dan air, wetland alamiah mencakup antara lain, rawa-rawa, padang rumput basah, lahan yang terkena pasang surut, dataran banjir, dan lahan basah di sepanjang saluran sungai.[4]

Adapun peran wetland adalah menyerap air pada musim hujan, menjadi air tanah yang akan dialirkan pada saat kelebihan air, menjadi cadangan air di musim kering, dan sebagai ruang terbuka taman wisata bagi penduduk serta dapat meningkatkan perekonomian di sekitarnya pada saat tidak tergenang. Wetland mempunyai manfaat untuk memperbaiki kualitas air yaitu dengan cara menahan unsur hara, mengurangi pengaruh buruk banjir dengan menahan air tersebut dan meningkatkan resapan air tanah, memulihkan kembali persediaan air tanah, menjadi ekosistem/tempat hidup untuk flora dan fauna khas wetland,dan penjernihan air dengan menggunakan tanaman seperti eceng gondok dan lain-lain.

Pemerintah Kota Bandung membuat Wetland Park Cisurupan di Cibiru, merupakan salah satu kawasan resapan air berupa kolam retensi untuk mengatasi banjir akibat meluapnya Sungai Ciloa di daerah Gedebage. Area ini pada awalnya berupa perkebunan dan sawah milik Pemerintah Kota Bandung yang tidak terurus.

Kawasan Wetland Park Cisurupan sudah beroperasi pada bulan Agustus 2019 dan memiliki luas lahan 10 hektar dengan kondisi tanah yang berkontur karena berada dikawasan dataran tinggi. Pada kawasan ini terdapat 19 kolam retensi, gazebo multifungsi, amphitheater, dan rumah kompos.

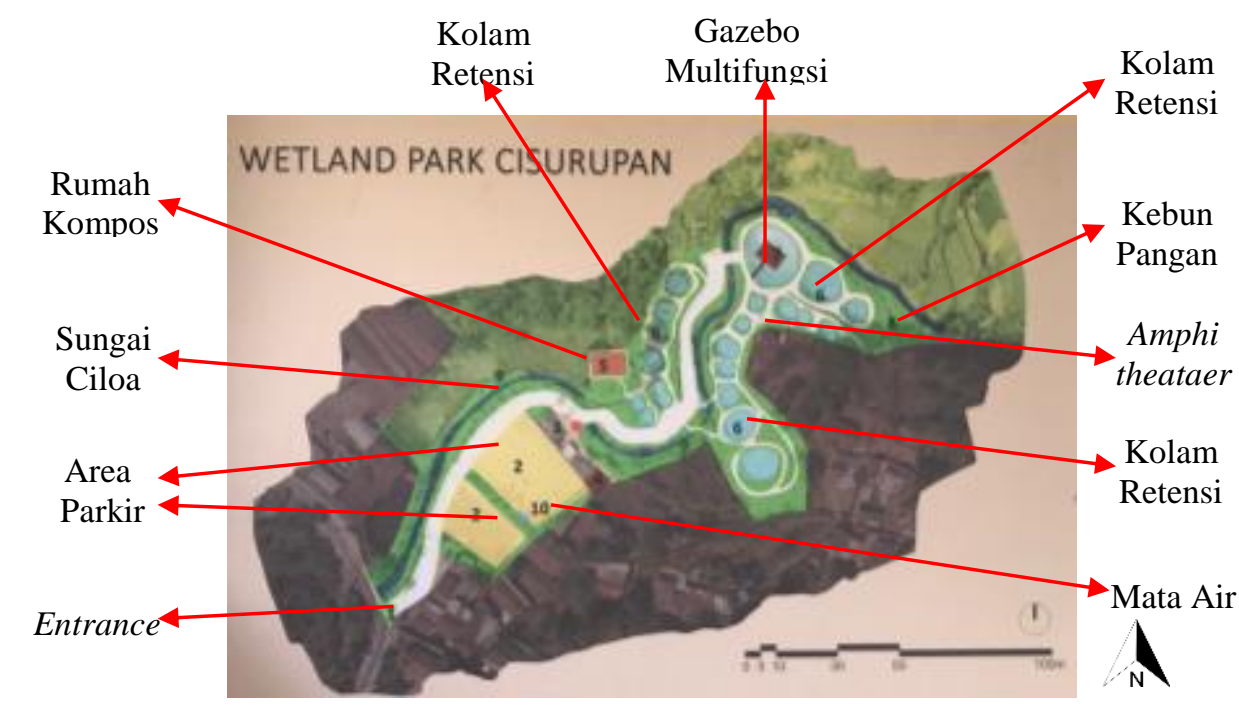


Gambar 1. Site Plan

Sumber: Dinas Pekerjaan Umum,2020, diolah.

Ketika musim hujan turun, debit air pada Sungai Ciloa ini sangat tinggi sehingga air meluap ke lingkungan sekitarnya, dan menimbulkan banjir.. Keberadaan kawasan ini diharapkan berperan sebagai daerah resapan air, salah satunya melalui wetland buatan yang berupa kolam retensi. Sirkulasi air dari buangan air hujan diatur melalui sungai untuk direkayasa dengan cara dibelokkan ke dalam kolam retensi. Dilengkapi dengan penataan landscape untuk menciptakan lingkungan yang sehat sebagai pengendali banjir, selain itu dapat dikembangkan potensi wisatanya.

\section{METODOLOGI}

Penelitian dilakukan menggunakan metode kualitatif dengan cara deskriptif analisis yaitu menyesuaikan beberapa fakta dan kondisi di lapangan, kemudian membandingkan dengan teori terkait, yaitu suitanable design dan suistanable infrastructure.

Pemahaman mengenai sustainable design atau desain berkelanjutan (juga disebut desain lingkungan, desain berkelanjutan secara lingkungan, desain kesadaran lingkungan, dll.) merupakan falsafah dalam merancang benda fisik, lingkungan nyata, dan layanan untuk memenuhi prinsip keberlanjutan secara ekonomi, sosial dan ekologi. Tujuan dari desain berkelanjutan adalah untuk "menghilangkan dampak lingkungan negatif sepenuhnya melalui desain yang terampil dan sensitif". Manifestasi desain berkelanjutan membutuhkan sumber daya terbarukan, dampak lingkungan minimal, dan menghubungkan orang dengan lingkungan alam. Menurut Jason F. McLennan (2004), sustainable design menekankan pencarian solusi rancangan yang seimbang terhadap permasalahan lingkungan, kenyamanan, estetika, serta biaya. Strategi dan teknologi yang memiliki dampak rendah terhadap lingkungan dan memperbaiki kenyamanan serta kualitas secara keseluruhan menurut pendekatan sustainable design antara lain adalah: Konservasi air, lansekap alamiah, preservasi lahan, renewable energy, ventilasi alami, penerangan alami, minimasi sampah konstruksi.[5]

Sonan Capital (2016), yang menyatakan bahwa infrastruktur berkelanjutan mengacu pada apa pun yang dibangun atau digunakan dengan cara yang berkontribusi terhadap keberlanjutan sumber daya alam secara keseluruhan. Sustainable Infrastructure memiliki 2 kategori utama, yaitu Traditional Infrastructure dan Nature Infrastructure.[6]

Dalam Traditional Infrastructure didalamnya terkait beberapa aspek antara lain: transportasi, bangunan, sanitasi dan telekomunikasi. Adapun pada Nature Infrastructure termasuk didalamnya aspek wetland, landscape, water management dan pengendalian alam.

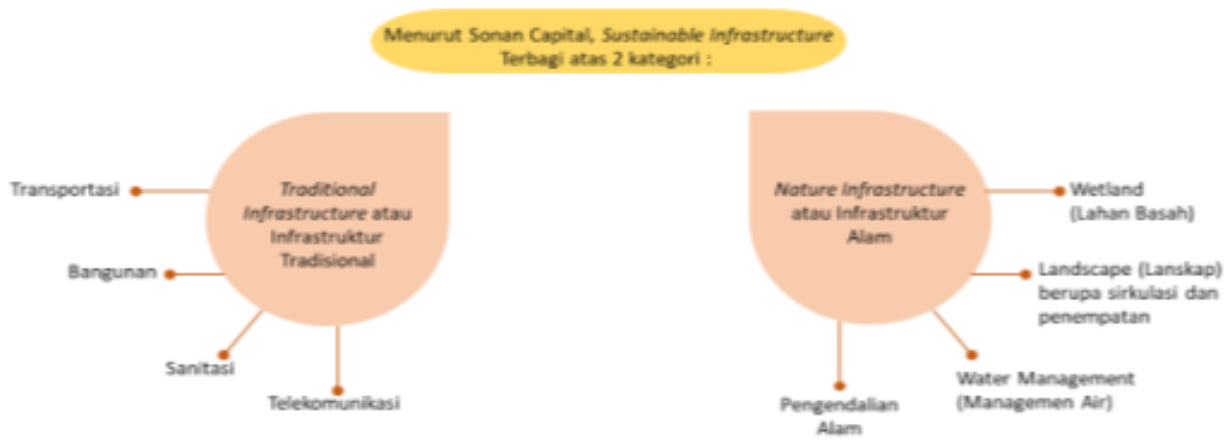

Gambar 2. Skema Suistanable Infrastucture

Sumber: Hasil Analisis, 2020

Dalam upaya penyediaan ruang terbuka bagi masyarakat, dapat dipahami bahwa terdapat interaksi yang rumit antara pribadi, ekologi dan faktor spasial fisik dalam membentuk persepsi, evaluasi dan penggunaan ruang public di perkotaan.[7]. Dalam rancangan lansekap berbasiskan wetland, integrasinya bersama ruang public dapat membawa banyak keuntungan seperti secara ekologis dengan terurainya limbah, secara biologis dengan terpenuhinya tambahan oksigen bagi biota 
aquatic, secara ekonomi dengan menambah nilai dan daya tarik suatu kawasan dan secara sosial dengan terciptanya lingkungan yang lebih baik serta nilai pendidikan yang didapat dari pengamatan dan penelitian.[8].

Pada penelitian di Wetland Park Cisurupan ini akan dibatasi membahas aspek-aspek yang berhubungan dengan unsur alam saja, yaitu aspek Nature infrastructure, dengan variabel analisisnya yaitu (1) Landscape (Lanskap) di dalam site yang mencakup penempatan area entrance, penempatan area parkir, sirkulasi kendaraan, pedestrian, penempatan area pembibitan, rekayasa area sungai, dan penempatan area komunal, (2) Zoning kolam retensi sebagai wetland (lahan basah) untuk pengendalian air hujan,

(3) Water management (manajemen air) berupa sirkulasi air pada sungai dan kolam retensi sebagai pengendali air hujan, dan (4) Pengendalian alam untuk dalam site dan luar site.

\section{HASIL DAN PEMBAHASAN}

\subsection{Analisis Aspek Landscape (Lanskap) di Kawasan Wetland Park Cisurupan}

Analisis Landscape (Lanskap) di Kawasan Wetland Park Cisurupan yang mencakup penataan pada area entrance, area parkir, sirkulasi kendaraan, sirkulasi pejalan kaki, area pembibitan, area rekayasa sungai, dan area komunal, selayaknya diarahkan agar tercipta suasana menarik dan penataan yang fungsional.

\subsubsection{Area Entrance}

Untuk memasuki kawasan diawali dengan adanya area entrance berupa jalan masuk selebar 6 meter. Di sekitar area entrance ini terdapat pepohonan sebagai komponen pembentuk ruang yang menghasilkan ruang orientasi bagi pengguna dan sebagai bayang-bayang peneduh.[9]. Pada area entrance ini disediakan signage (penanda) berupa peta lokasi sebagai informasi dan sculpture bambu yang dibuat setinggi 10 meter sebagai penanda bahwa kawasan yang akan didatangi sudah mendekat. Gate pada pintu masuk utama tidak didisain secara khusus, tidak ada penanda, sehingga memberi kesan kurang menerima. Untuk menarik perhatian pengunjung, sebaiknya sclupture bambu yang ada perlu sentuhan disain estetika yang baik.

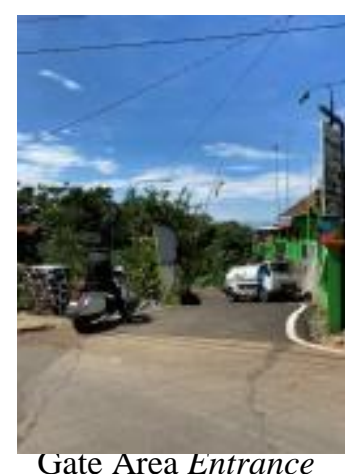

Gate Area Entrance

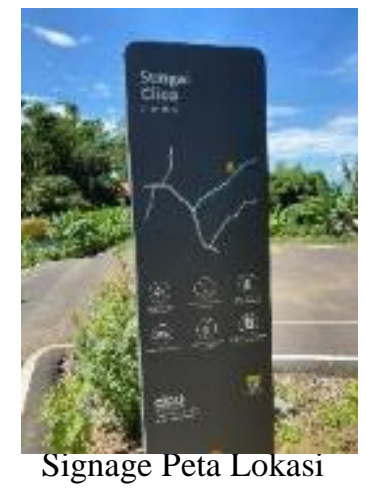

Gambar 3. Area Entrance

Sumber: data lapangan,2020

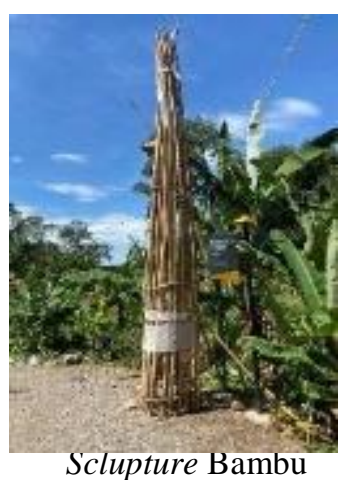

Sclupture Bambu

\subsubsection{Area Parkir, Sirkulasi Kendaraan, dan Pejalan Kaki}

Setelah melalui area entrance, akan ditemui area parkir dan sirkulasi kendaraan yang menggunakan bahan penutup jalan aspal. Area parkir pada kawasan ini memiliki 2 area yang cukup luas, dapat menampung 36 mobil dan 50 motor yang dilindungi oleh pepohonan yang meneduhkan di area tersebut. Pencapaian untuk menuju area parkir ini dibuat tidak langsung dengan jalan yang dibuat meliuk-liuk, diharapkan agar pengunjung merasakan pengalaman ruang yang dinamis dan kesejukan kawasan tersebut dengan adanya pepohonan disekitar jalan. 


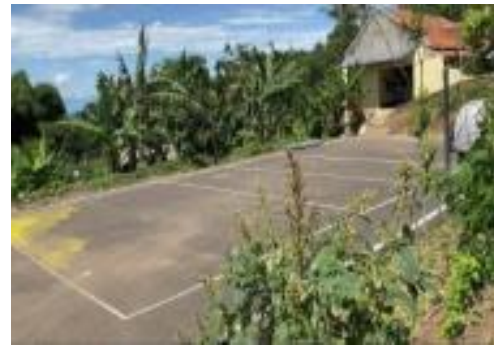

Area Parkir 1

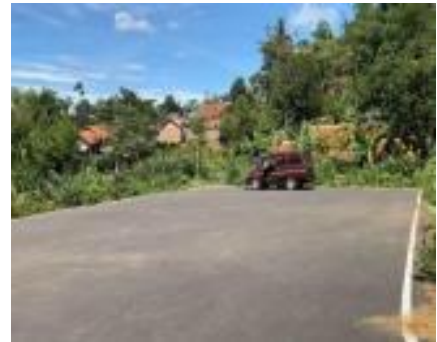

Area Parkir 2

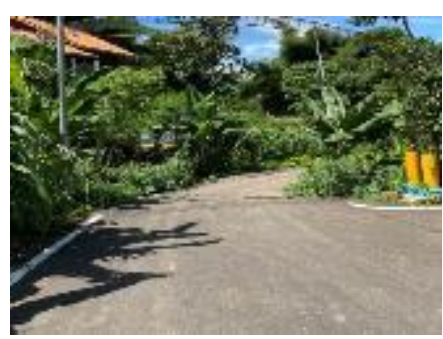

Sirkulasi Kendaraan

Gambar 4. Area Parkir

Sumber: data lapangan, 2020

Adapun area sirkulasi untuk pejalan kaki menggunakan bebatuan (gravel) berkesan alami, dibuat dengan lebar 3.5 meter dan bisa dilalui 5-6 orang jalan berdampingan, sebagai respon terhadap budaya masyarakat yang datang berkelompok. Untuk area pedestrian disekitar kolam dibuat dengan lebar 1 meter yang bisa dilalui 1 orang.

Disekitar area pedestrian ini dilengkapi dengan garden furniture yang terdiri dari batu hiasan berbentuk bola, lampu taman berupa lampu hias dan lampu penerangan jalan umum, tempat duduk dari bahan kayu dan bambu, signage sebagai penanda lokasi dan fungsi, dan elemen pagar sebagai pembatas dan pelengkap lanskap.

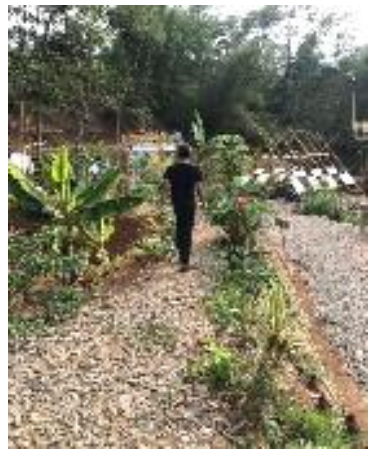

Bebatuan

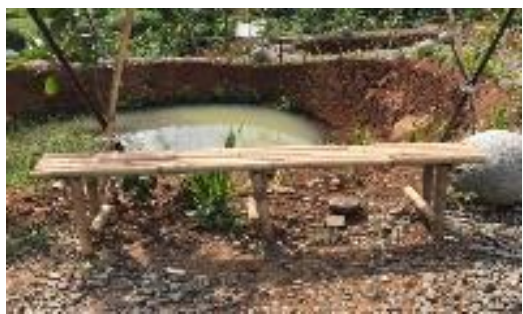

Tempat Duduk

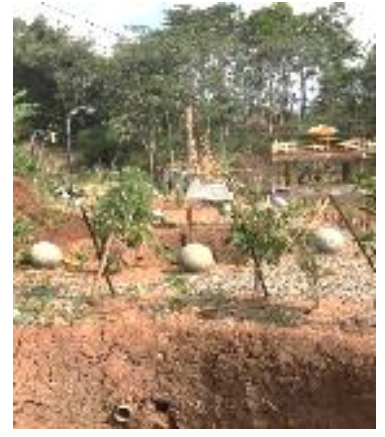

Batu Hiasan

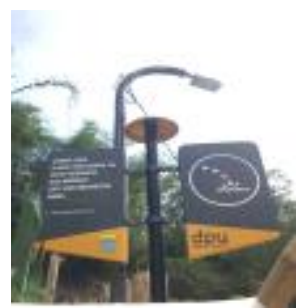

Signage
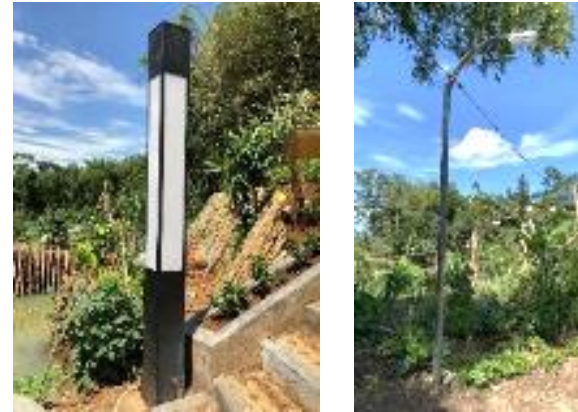

Lampu Taman

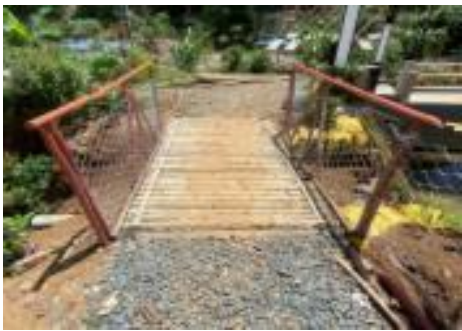

Pagar

\section{Gambar 5. Furnitur Taman}

Sumber: data lapangan, 2020

\subsubsection{Area Pembibitan, Area Sungai, dan Area Komunal}

Area pembibitan yang terletak di bagian Utara disediakan sebagai area untuk pembibitan tanaman yang akan digunakan di kawasan ini. Area ini juga dilengkapi dengan rumah kompos, yang berupa banguana dengan menggunakan material batu alam, batu bata, dan atap dari tanah liat atau genteng. Penempatan area pembibitan ini berada sejajar dengan jalan utama, dan berada pada kontur yang berbeda, sehingga pencapaian menuju area pembibitan dari area kawasan Wetland harus menggunakan tangga. 
Adapun area alur sungai yang melengkung berliku ditanamani pepohonan ditepiannya, sehingga memberi kesan sungai terasa sejuk dan menguatkan tepian sungai.

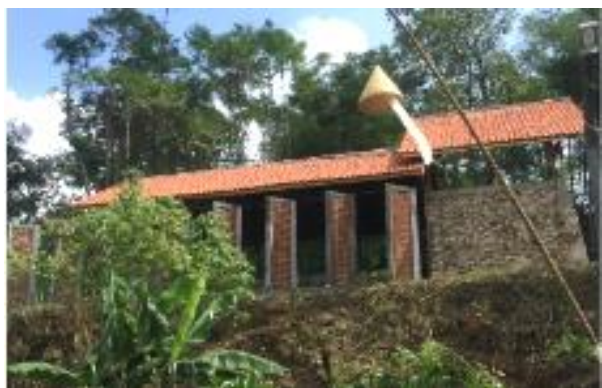

Rumah Kompos
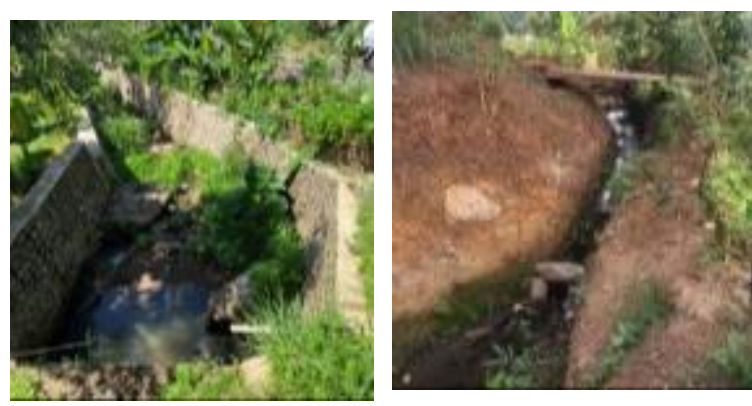

Area Sungai

Gambar 6. Are Pembibitan dan sungai

Sumber: data lapangan, 2020

Wetland Park juga dilengkapi dengan area komunal sebagai area berkumpul pengunjung, yang dapat memuat kurang lebih 100 orang pengunjung yang dilengkapi dengan gazebo mutifungsi 2 lantai berukuran $5 \times 6 \mathrm{~m} 2$ yang ditempatkan ditengah kolam air . Gazebo juga berfungsi untuk berteduh dari panas dan hujan. Pada bagian atap dak gazebo ini dapat digunakan pengunjung untuk menikmati suasana sekitar secara keseluruhan. untuk mendapatkan suasana yang lain. Selain itu juga terdapat amphitheater yang dapat digunakan untuk pengunjung berduduk santai dan terkadang dapat digunakan untuk acara tertentu. Tangga amphitheater ini dibuat menggunakan material grass block agar tanaman tetap bisa tumbuh disela-selanyajuga. Amphitheater juga berfungsi sebagai tempat pengunjung berkumpul, dan saling berinteraksi menikmati suasana sekitar. Penempatan area komunal ini ditempatkan ditengah kawasan sebagai pusat aktivitas pengunjung.

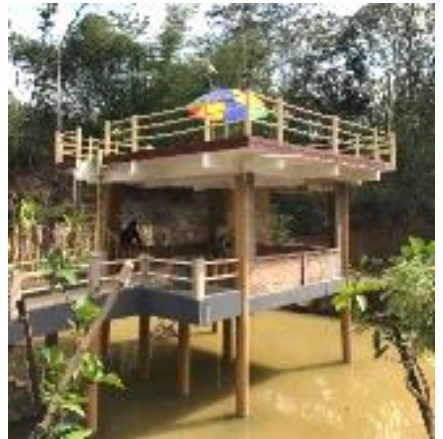

Gazebo Multifungsi

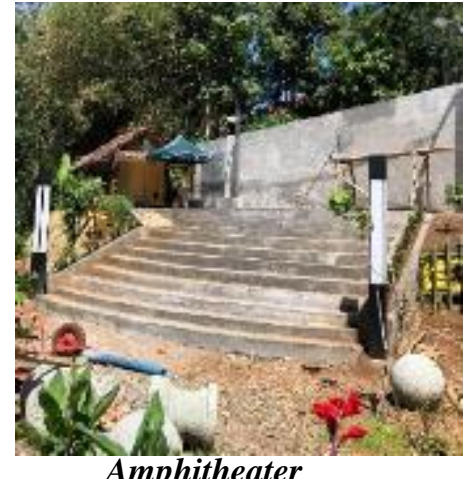

Amphitheater

Gambar 7. Area Komunal

Sumber: data lapangan,2020

\subsection{Analisis Aspek Wetland (Lahan Basah) di Kawasan Wetland Park Cisurupan}

Analisis aspek wetland (lahan basah) ini mencakup keberadaan dan situasi sungai dan kolam retensi. Sungai Ciloa yang melintasi kawasan ini merupakan sungai yang bersifat permanen karena memang sudah ada dari dulu dengan air yang mengalir secara alami. Sungai ini memiliki lebar 2 meter sampai 3 meter dengan kedalaman sungai 1,5 meter sampai 2 meter dari jalan. Sungai ini mempunyai debit air yang biasa saja pada musim kemarau, namun berbeda menjadi sangat tinggi ketika musim hujan. Kondisi ini sering mengakibatkan banjir karena sungai tidak mampu mengalirkan air secara baik sehingga air hujan di sungai ini meluap ke area sekitarnya. 


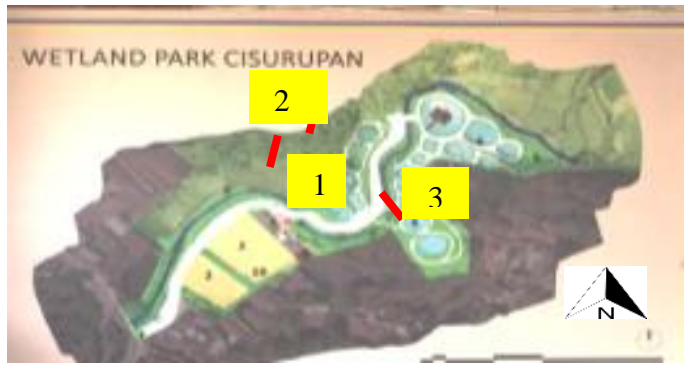

Gambar 8. Peta kunci

Sumber: Dinas Pekerjaan Umum, diolah 2020

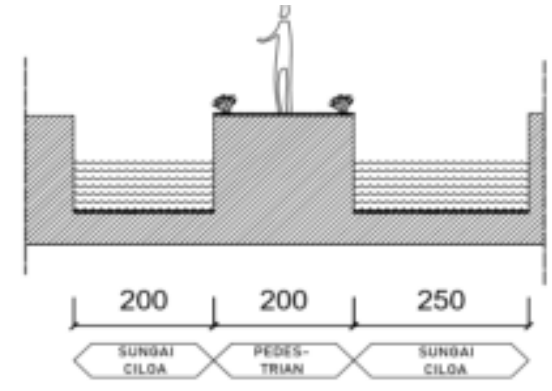

Gambar 9. Potongan sungai (1)

Sumber: Hasil Analisis, 2020

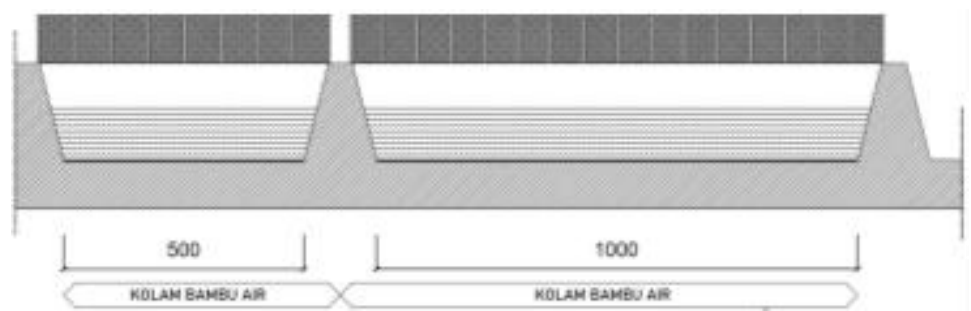

Gambar 9. Potongan Kolam retensi (2)

Sumber: Hasil Analisis, 2020

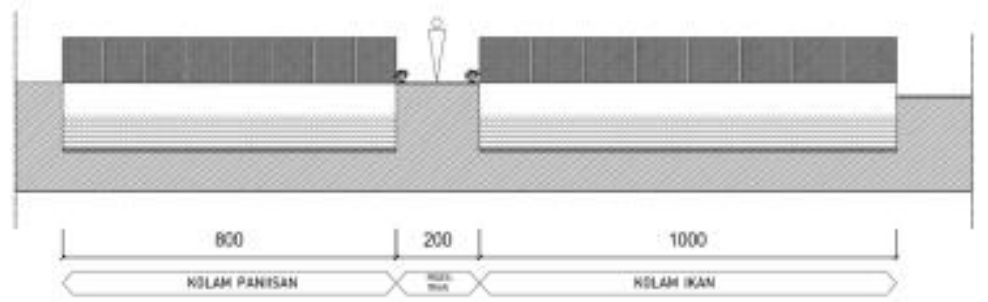

Gambar 10. Potongan Kolam retensi (3)

Sumber: Hasil Analisis, 2020

Sungai Ciloa ini jika dilihat dari jenisnya termasuk kedalam lahan basah alami, yang mengalirkan air berlebih disaat musim hujan. Melalui upaya rekayasa, aliran air di belokkan menuju kolam retensi menggunakan bendungan yang disebut bronjong berupa penghalang yang ditempatkan dalam aliran untuk menyempitkan aliran air dan mengarahkannya ke sumur resapan.[10].

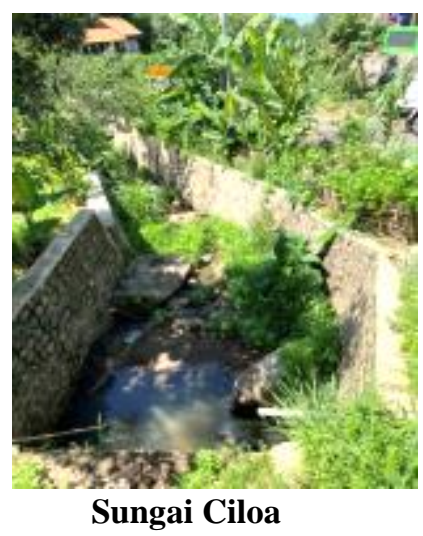

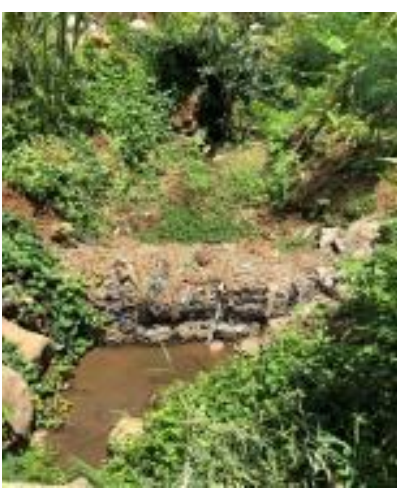

Bendungan

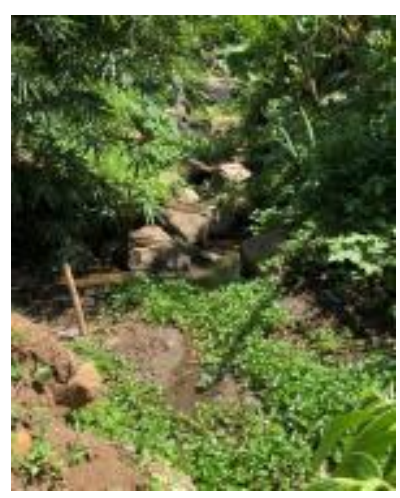

Sungai rekayasa

Gambar 11. Kondisi sungai alami dan rekayasa serta bendungan Sumber: data lapangan,2020 
Sebagai pengendali banjir tersebut, pada area ini dibuat kolam-kolam retensi yang terdiri dari 19 kolam dengan ukuran diameter kolam 4 meter sampai 18 meter dengan ketinggian kolam 2 meter sampai 4 meter. Kolam retensi juga berperan sebagai kolam wisata yang dapat digunakan untuk berenang atau berendam anak kecil, dan juga sebagian kolam sebagai budidaya ikan. Kolam retensi ini bermanfaat untuk mengurangi pengaruh buruk banjir di daerah Gedebage, Kota Bandung, dengan upaya menahan air tersebut dan meresapkan terlebih dahulu sebelum di alirkan kembali ke Sungai Ciloa.

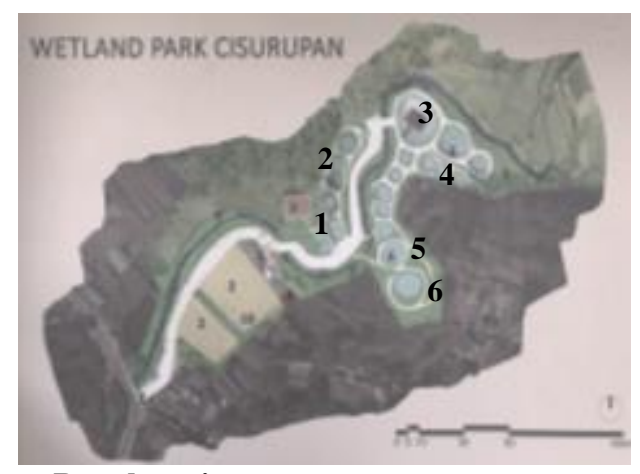

Peta kunci

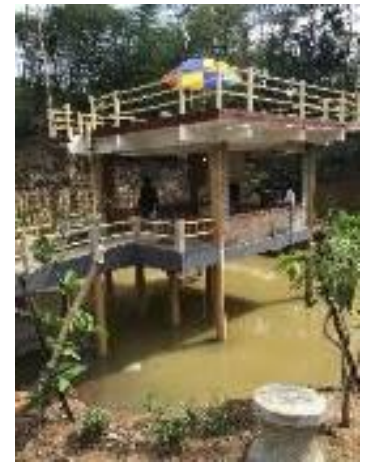

(3) Kolam Deras

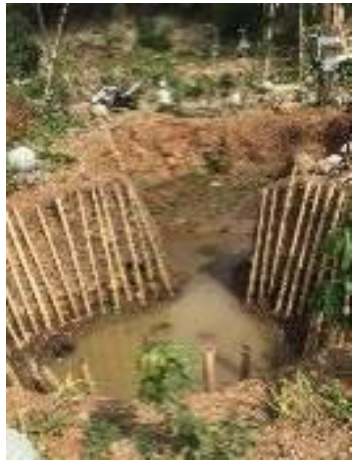

(4) Kolam Dalam

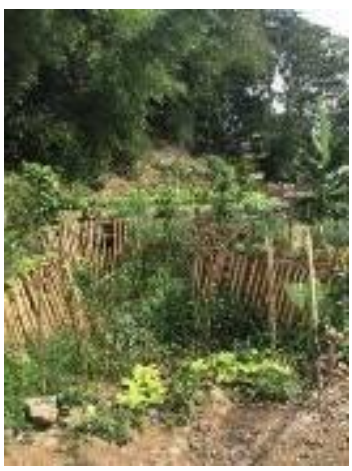

(1) Kolam Bambu Air

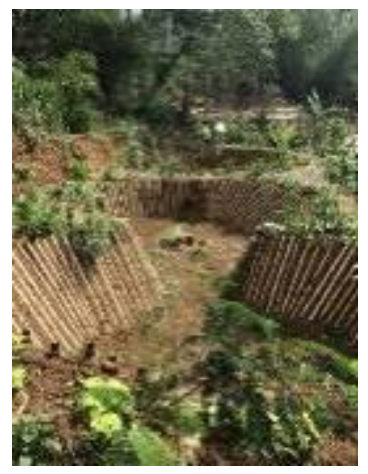

(2) Kolam Pete

Gambar 12. Kondisi kolam pengendali banjir

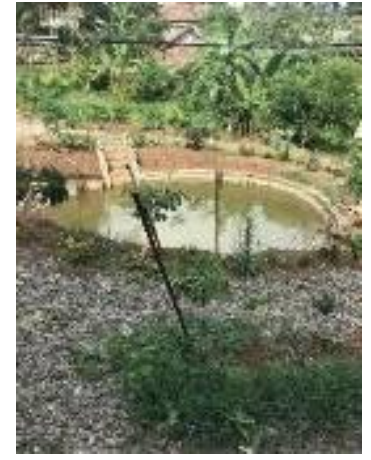

(5) Kolam Ikan

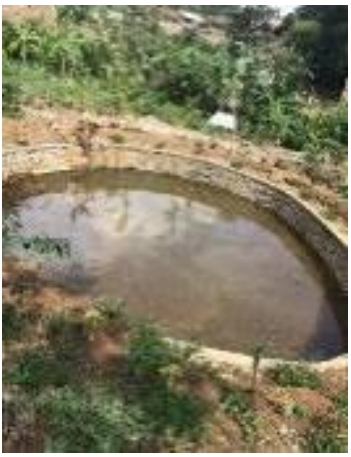

(6) Kolam Rendam Paniisan

\subsection{Analisis Aspek Water Management (Manajemen Air) di Kawasan Wetland Park Cisurupan} Aspek_Water management (Manajemen Air) yang akan dianalisis pada penelitian ini terutama adalah mengenai sirkulasi airnya. Sirkulasi air pada kawasan ini berasal dari buangan air hujan melalui Sungai Ciloa. Sirkulasi air dari Sungai Ciloa ini direkayasa dengan dibelokan untuk dialirkan menuju kolam retensi ini menggunakan saluran pembuangan air diatas tanah (open channels) dengan menggunakan pipa diatas tanah yang menghubungan satu kolam dengan kolam yang lainnya sehingga volume air yang berlebih dari aliran sungai, dapat masuk dan diserap di seluruh kolam retensi yang sudah disediakan, Adapun lebihan air yang tak terserap akan dialirkan lagi menuju sungai Ciloa.Pada gambar 13 dapat terlihat aliran sungai alami yang berwarna kuning, lalu direkayasa pada aliran warna merah, dialirkan ke kolam retensi , 


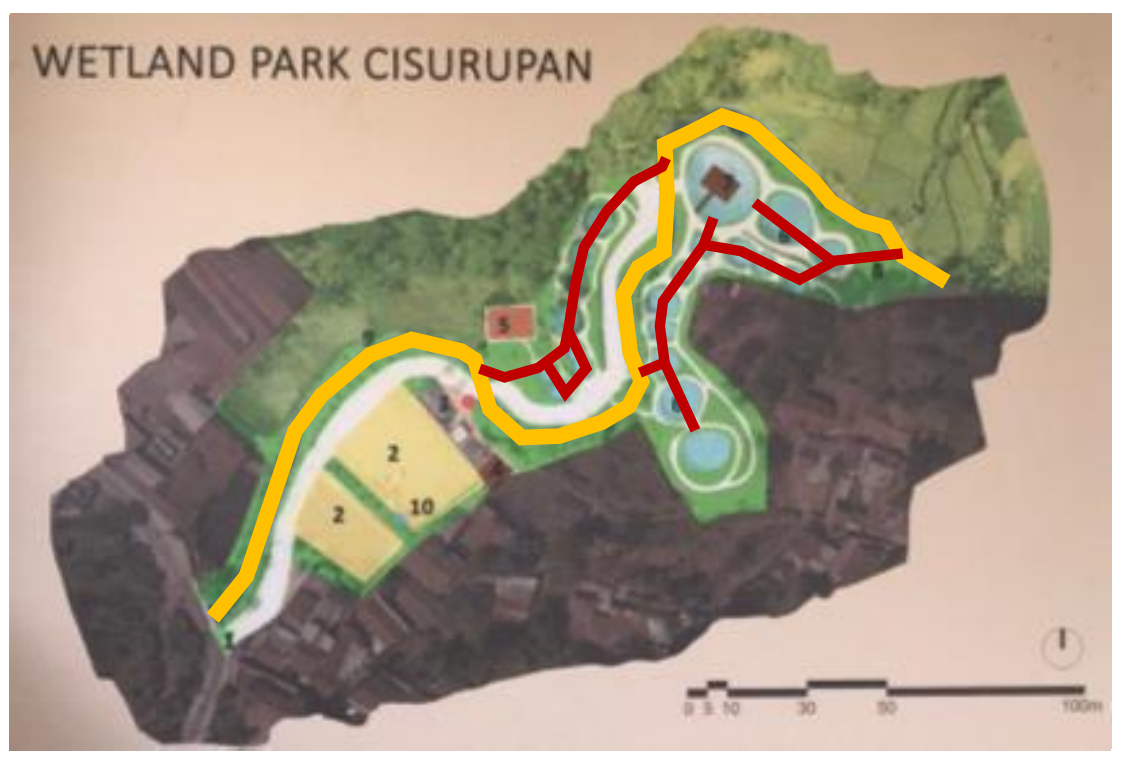

Gambar 13. Kondisi manajemen sirkulasi air Sumber: Dinas Pekerjaan Umum, 2020, diolah.
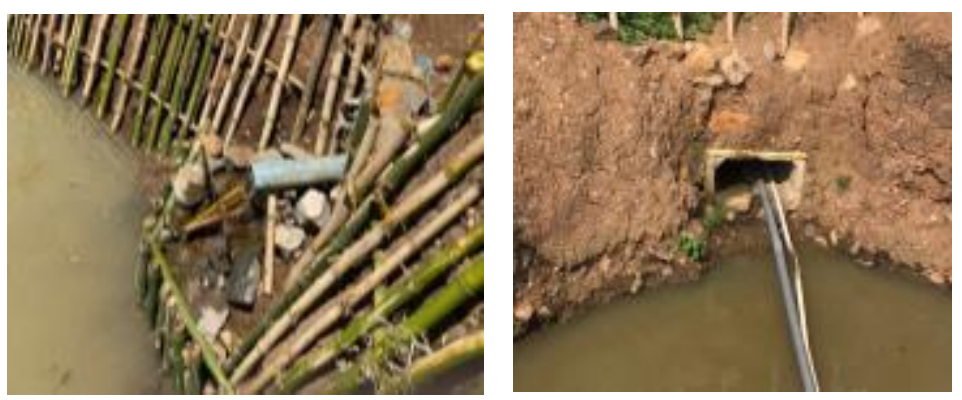

Gambar 14. Kondisi pipa air penghubung antar kolam Sumber: data lapangan, 2020

\subsection{Analisis Aspek Pengendalian Alam di Kawasan Wetland Park Cisurupan}

Aspek pengendalian alam yang ada berupa penataan tebing tahanan tanah,, kawasan permakultur, dan konservasi kawasan hijau. Tebing tahanan atau biasa disebut dinding penahan ini dibuat setinggi 3 meter terdapat pada bagian seluruh dinding kolam. Dinding penahan tanah dibuat dalam kelerengan yg cukup curam sekira $60 \%$, dan untuk menjaga agar tebing tetap kuat dan tidak longsor, selain dibuat cerucuk bambu, juga ditanami pepohonan bambu dan karet.

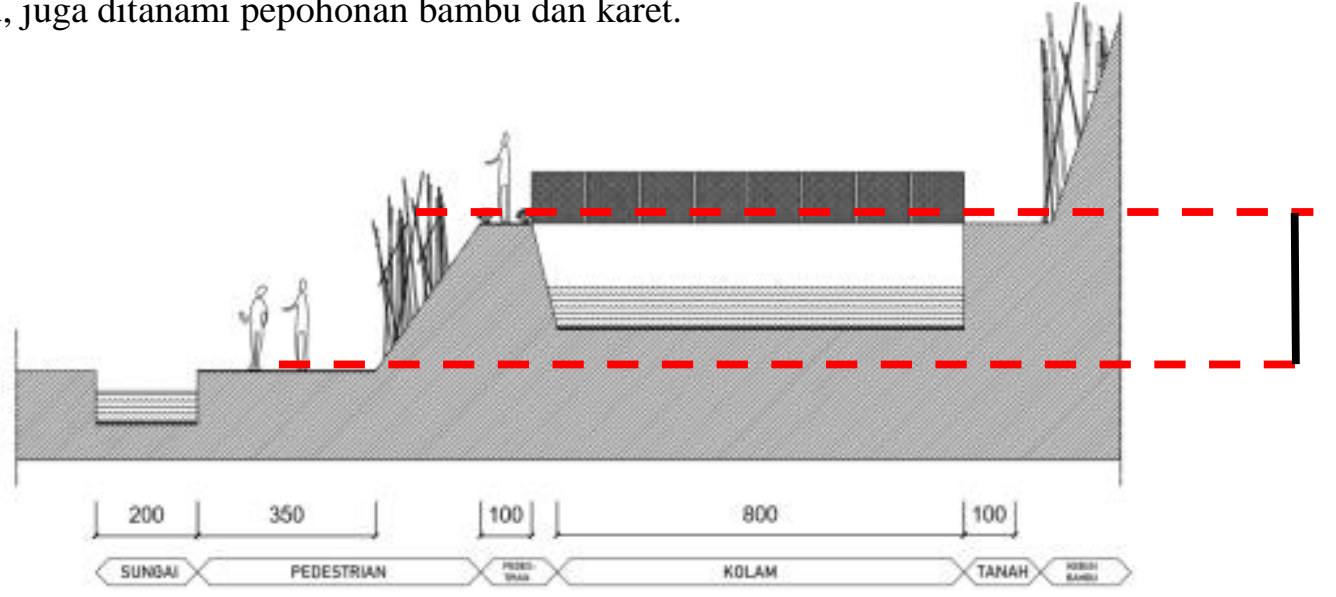

Gambar 15. Potongan tebing tahanan

Sumber: Hasil Analisis, 2020 

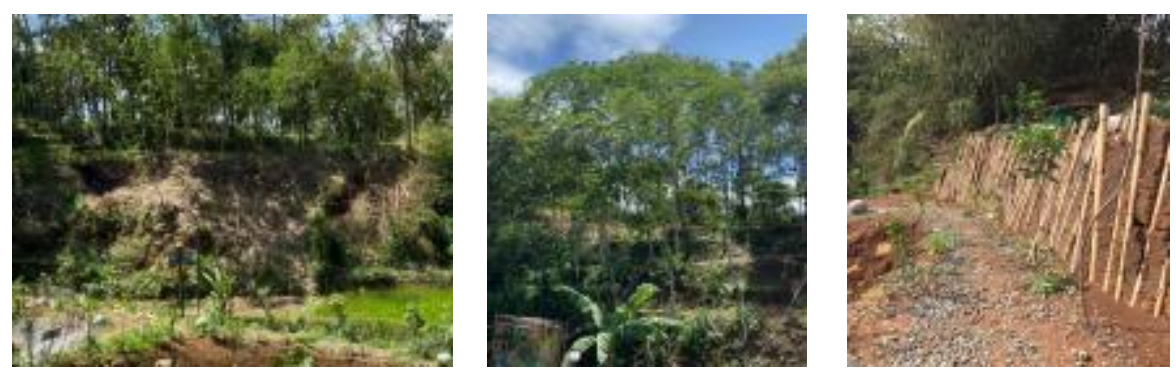

Gambar 16. Suasana di sekitar tebing tahanan

Sumber: data lapangan, 2020

Adapun kawasan permakultur yang berada di sekitar kolam-kolam retensi ditanami semak, perdu, dan beraneka pohon. Jenis-jenis tanaman yang ada terdiri dari tanaman buah sawo, pete, nangka, rambutan, pepaya, singkong, belimbing, jambu air, matoa, pisang, pohon bambu, pohon mahoni, pohon teratai, dan pohon karet. Kawasan permakultur ini berfungsi agar kawasan Wetland Park Cisurupan ini menjadi kawasan yang mempunyai tata ruang yang lebih efisien dan membuat lingkungan menjadi lebih sehat dengan fungsi penyerapan air disekitarnya, serta membuat kokoh tebing tahanan. Kawasan ini juga berfungsi sebagai kawasan wisata dan sarana edukasi untuk para pengunjung, dengan suasana hijau dan udara yang segar, serta memberikan keterangan penamaan pohon -pohon yang tumbuh.disana.
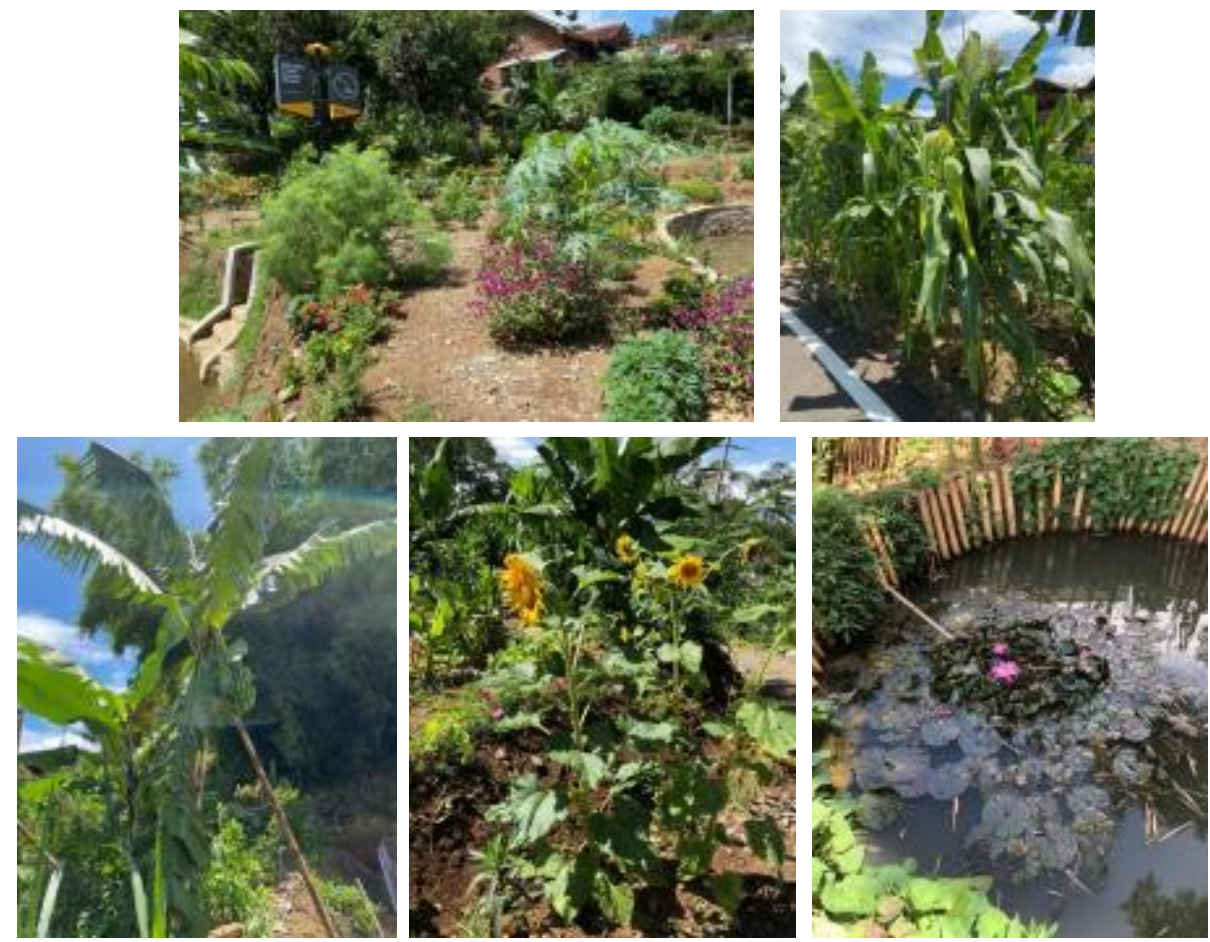

Gambar 17. Semak, perdu dan tanaman air Sumber: data lapangan,2020

Konservasi kawasan hijau pada Kawasan Wetland Park Cisurupan ini diupayakan dengan menanam pepohonan yang berguna untuk di dalam site dan di luar site. Pohon yang ditanam berupa tanaman tropis dengan jenis tanaman keras dan bentuknya tidak beraturan dengan tinggi antara 3 meter sampai 12 meter, yautu pohon karet dan bambu. Konservasi kawasan hijau ini berfungsi sebagai kawasan hutan yang menjadi bagian dari sistem sirkulasi udara untuk di dalam dan luar site. Kawasan hijau ini 
juga berfungsi sebagai penyerap air hujan, pengontrol angin dan sinar matahari, sebagai penghasil bayang-bayang keteduhan di kala musim kemarau, dan sebagai komponen pembatas pandangan.
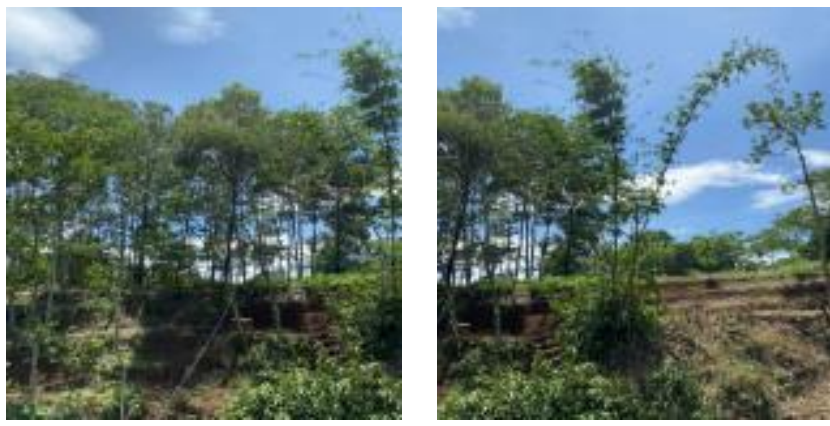

Gambar 18. Konservasi kawasan hijau, pohon karet dan bambu Sumber: data lapangan, 2020

\section{SIMPULAN}

Berdasarkan hasil pengamatan dan penelitian dapat disimpulkan bahwa aspek Nature Infrastructure dalam konsep Sustainable Infrastructure pada Kawasan Wetland Park Cisurupan, sebagai berikut :

1. Landscape (lanskap), dilihat dari elemen pembentuk lanskap dan unsur-unsur desain lanskap sudah lengkap dan nampaknya perlu ditingkatkan lagi penataan lanskap dan perawatannya agar menambah nilai estetika kawasan sebagai ruang terbuka hijau dan publik, serta menambah nilai daya tarik wisatanya.

2. Jenis wetland (lahan basah) sampai saat ini dapat mendukung pengendalian banjir dengan adanya kolam retensi sebagai kolam resapan air hujan yang datang dari Sungai Ciloa.

3. Water Management (Manajemen Air) ditinjau dari sirkulasi airnya dapat mengendalikan luapan dengan cara direkayasa yang dibelokkan menuju kolam retensi sehingga air hujan yang meluap dari Sungai Ciloa bisa di resapkan terlebih dahulu sebelum dialirkan kembali menuju Sungai Ciloa.

4. Penanaman pohon pada tebing tahanan ditinjau jenis tanaman dan penempatannya dapat mendukung fungsi dinding penahan dari longsoran tanah..

Hasil analisis penelitian terhadap penilaian pada setiap masing-masing bahasan variable saling terkait satu dengan yang lainnya, sehingga dalam penilaian sustainable infrastructure khususnya nature infrastructure kelengkapan unsur-unsurnya dapat dinyatakan sudah terpenuhi. Perlu upaya yang baik untuk meningkatkan kualitas, menjaga dan merawatnya agar mempunyai nilai manfaat yang baik untuk Kawasan Wetland Park dan lingkungan sekitarnya.

\section{DAFTAR PUSTAKA}

[1] Rizal, Reda, (2017). Analisis Kualitas Lingkungan, Penerbit Lembaga Penelitian dan Pengabdian Masyarakat UPN Veteran Jakarta., ISBN 978-602-19087-6-1.

[2] Müller\& Willemen L.,(2009). Ecosystem Services, in the Landscape Scale: The Need for Integrative Approches, Landscape Online, pp. 111

[3] Fatmawati, Annisa, (2020). Lahan Basah: Pengertian, Sebaran, dan Jenis. Foresteract.com. Tersedia dalam https://foresteract.com/lahan-basah/. Diakses 2 Febuari 2021.

[4] UN-HABITAT, (2008). Constructed Wetlands Manual. (Vol. 978-92-1-131963-7)-HABITAT Water for Asian Cities Programme

[5] F.Mclennan, Jason, (2004). The Philosophy Of Sustainable Design, Ecotone LLC, Kansas City

[6] Capital, Sonan, 2016, 2015 Annual Impact Report; sonencapital, San Fransisco. 
[7] Irvine, K N., Wright, P. D, Payne, S. R. Fuller, R. A, Painter, B, and Gaston, K. J, (2009) Green space, soundscape and urban sustainability: an interdisciplinary, empirical study, Local Environment: The International Journal of Justice and Sustainability, 14, pp. 155-172

[8] Tian,M,(2011). Application of Constructed Wetland Technology in Urban Landscape Designs, Advanced Materials Research Vols. 211-212, pp.939-943.

[9] Hakim, Rustam, (2014). Komponen Perancangan Arsitektur Lanskap, Bumi Aksara, Jakarta.

[10] O Schwad, Glenn; D Fangmeier, Dermar; J Elliot, William, (1996). Soil and Water Management Systems,. John Willey \& Sons, Inc, United States of America. 